\title{
Papillary Squamous Cell Carcinoma: A Rare Variant of Oral Squamous Cell Carcinoma
}

Dr. Sujata S. Kumbhar ${ }^{1 *}$, Dr. Avinash Mane ${ }^{2}$, Dr. Garima Agarwal ${ }^{3}$, Dr. Shoaib Khoja ${ }^{3}$, Dr. Vaidehi Nagar ${ }^{3}$, Dr. Divya Bhrambhatt $^{3}$

${ }^{1}$ Associate Professor, ${ }^{2}$ Assistant Professor, ${ }^{3}$ Tutor, Department of Pathology, Krishna Institute of Medical Sciences, Deemed to be University, Karad 411510, Maharashtra, India

DOI: $10.36347 /$ simcr.2020.v08i06.015

| Received: 20.05.2020 | Accepted: 03.06.2020 | Published: 30.06 .2020

*Corresponding author: Dr. Sujata S. Kumbhar

Abstract

One of the most common malignancies of oral cavity is Squamous Cell Carcinoma but its variant Papillary Squamous Cell Carcinoma (PSCC) has rarely been reported. An accurate diagnosis important for both prognostic and therapeutic purposes. We present a case of 50 years old man who came to the surgery out patient department with the complaint of swelling and pain in the left lower alveolus which was diagnosed by histopathology as Papillary Squamous Cell Carcinoma.

Keywords: Papillary Squamous cell carcinoma, oral cavity.

Copyright @ 2020: This is an open-access article distributed under the terms of the Creative Commons Attribution license which permits unrestricted use, distribution, and reproduction in any medium for non-commercial use (NonCommercial, or CC-BY-NC) provided the original author and source are credited.

\section{INTRODUCTION}

Parkhill in 1986 described that Papillary Squamous Cell Carcinoma is clinically rare variant of Squamous Cell Carcinoma of the upper aerodigestive tract mucosa. Very few cases have been reported so far [1]. Men in the $6^{\text {th }}$ and $7^{\text {th }}$ decades are predominantly involved [2, 3]. Larynx, oropharynx and nasopharynx are most commonly involved Papillary Squamous Cell Carcinoma. Herewith, a case of papillary Squamous Cell Carcinoma of the oral cavity has been reported to focus its clinical features and histopathological pattern.

\section{CASE RePORT}

A 50 years old man reported to the out patient department with the complaint of swelling and pain in the left lower alveolus since 15 days. Patient was apparantly healthy, moderately built and nourished with no known systemic illness. History revealed that a small swelling was seen 15 days back in the lower alveolus which had progressed to the present size and later ulceroproliferative growth developed which was associated with pain. Patient had a history of tobacco chewing since 40 years. Biopsy from left lower alveolus was reported as well differentiated Squamous Cell Carcinoma. Radioimaging CT Scan of neck was done which revealed soft tissue lesion in gingivobuccal area on the left side causing erosion and destruction of body of mandible with extensions suggestive of neoplastic etiology and multiple subcentimetric lymph node were likely reactive.

Complete excision of the lesion with left side neck dissection and right side Level I lymph node dissection was performed and sent to the Department of Surgical Pathology for histopathological examination.

\section{Gross Examination}

Grossly a grey white ulceroexophytic growth measuring $6 \times 3.5 \times 3.2 \mathrm{~cm}$ is seen involving left buccal mucosa, left sulcus, and left gingiva. Cut section of the growth was grey white and firm (Fig-1).

\section{Microscopic Features}

The tumor showed numerous exophytic papillary projection of hyerkeratinized atypical squamous epithelium with fibrovascular cores. Individual cells show basilar hyperplasia, increased nuclear / cytoplasmic ratio, nuclear hyperchromatism, nuclear pleomorphism and abnormal mitosis. Epithelium showed apoptotic bodies with minimal crowding. Stromal invasion was also seen. So the diagnosis of Papillary Squamous Cell Carcinoma was made (Fig-2). 


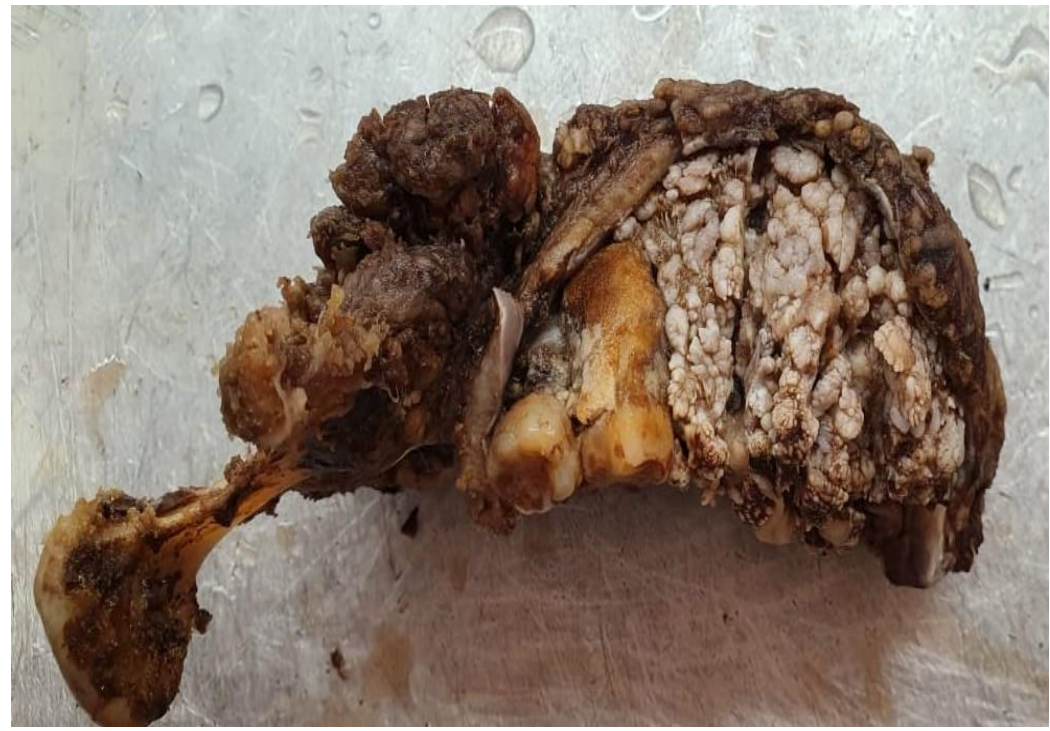

Fig-1: Grey white ulceroexophytic growth

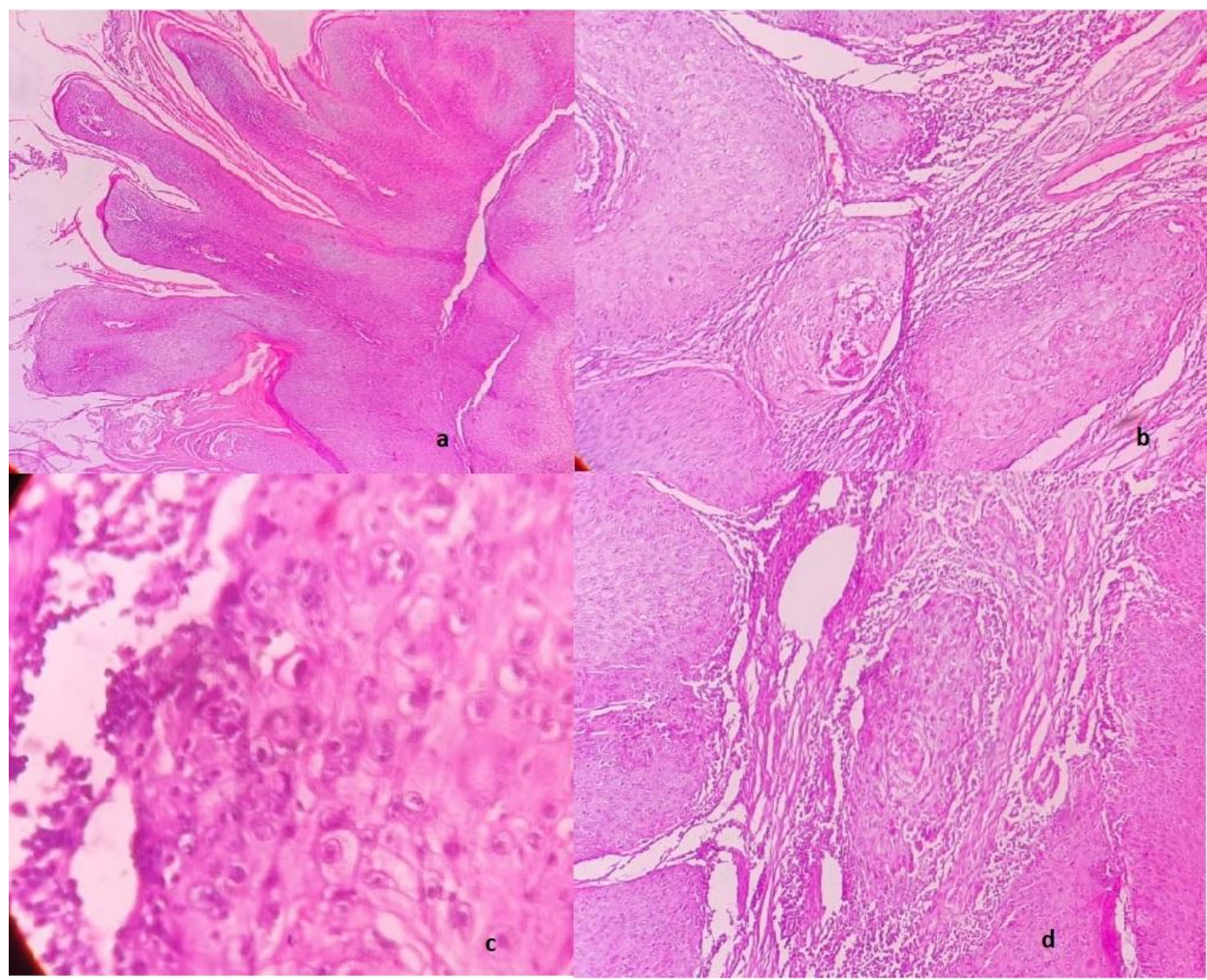

Fig-2: a: Exophytic papillary projections of the hyperkeratinised stratified squamous epithelium (H\&E, 40X); b,c: Epithelial cell dysplasia with individual cell hyperkeratinised $(\mathrm{H} \& \mathrm{E}, 100 \mathrm{X}, 400 \mathrm{X})$; d: Invasion of tumor cells $(\mathrm{H} \& \mathrm{E}, 100 \mathrm{X})$

\section{DISCUSSION}

Papillary Squamous Cell Carcinoma is clinically rare variant of Squamous Cell Carcinoma of the upper aerodigestive tract mucosa. Very few cases have been reported [1]. Predominantly in the $6^{\text {th }}$ and $7^{\text {th }}$ decade of men mostly involving Larynx, oropharynx and nasopharynx. Papillary Squamous Cell Carcinoma most often presents as a soft, friable, polypoidal, exophytic and papillary tumor.
Smoking and alcoholism is the most significant etiologies for the Papillary Squamous Cell Carcinoma [3]. There are many similarities between Papillary Squamous Cell Carcinoma and Squamous Cell Papillomas due to their clinical and histopathological findings, therefore it was postulated that HPV might be an important etiological factor for Papillary Squamous Cell Carcinoma [3, 4]. Latest techniques are used to demonstrate the frequent 
association of high risk HPV-16 in the sinonasal tract, oropharynx and larynx. However it has not been proved in any studies about the correlation of HPV in oral Papillary Squamous Cell Carcinoma.[5]

Macroscopically, Verrucous carcinoma shows exophytic, papillary and warty appearance. Lesion might appear soft to firm in consistency, they may arise from broad ligment or a narrows pedicle/ stalk [6]. Microscopically at low power they appear similar to sinonasal papillomas [2]. These lesions typically demonstrate a papillary pattern consisting of multiple, thin, delicate filiform, finger like papillary projections with fibrovascular cores [1]. The fibrovascular cores are covered by neoplastic, immature basaloid cells or more pleomorphic cells and shows minimal keratosis. The papillary projections are covered with a stratified squamous epithelium that shows features of malignancy like increased nuclear to cytoplasmic ratios, nuclear irregularities, and numerous mitotic figures located throughout the entire thickness of the epithelium. Sometimes it is also associated with the chronic inflammatory response [6]. Koilocytic atypia is frequently seen, which is seen as hyperchromatic, crenated nuclei surrounded by clear halo of cytoplasm and an accentuated cell border. Single or multiple nests of tumor cells with dense lymphocytic inflammation at the tumor stroma interface is usually seen in the stromal invasion [7]. Specimen resection should be done carefully for invasion because it behaves similarly to conventional type Squamous cell carcinoma

There are 2 morphological types of Papillary Squamous Cell Carcinoma which are being identidied:

- A Keratinising (K) type, in which the dyplastic epithelium showed maturation trend with minimal surface parakeratin.

- A non- keratinising (NK) type, in which papillae are covered with immature basaloid cells [7].

The present study showed keratising type of Papillary Squamous Cell Carcinoma. Differential diagnosis of Papillary Squamous Cell Carcinoma with their clinical and histopathological findings are very similar to solitary papillomas and verrucous carcinoma. The most common differential diagnosis include sinonasal or Schneiderian papillomas.

It is currently recommended that non invasive Papillary Squamous Cell Carcinoma be treated by complete surgical excision. And the treatment of invasive Papillary Squamous Cell Carcinoma depends on there low to moderate malignancy staging. Supplement radiotherapy and chemotherapy are the other treatment methods for Papillary Squamous Cell Carcinoma. It is presumed in Papillary Squamous Cell Carcinoma distant metastasis is rare and there prognosis is good.

\section{CONCLUSION}

Papillary Squamous Cell Carcinoma is a very rare variant of Squamous Cell Carcinoma of oral cavity. It is must for the pathologist to differentiate Papillary Squamous Cell Carcinoma from conventional Squamous Cell Carcinoma and other papillomas and verrucous carcinoma, as the prognosis is good in Papillary Squamous Cell Carcinoma than other diseases. Eventually, therapeutic modalities may be modified on the basis of the overall excellent prognosis of patient with Papillary Squamous Cell Carcinoma.

Conflict of Interest Statement: The authors have no conflict of interest.

\section{REFERENCES}

1. Ding Y, Ma L, Shi L, Feng J, Liu W, Zhou Z. Papillary squamous cell carcinoma of the oral mucosa: a clinicopathologic and immunohistochemical study of 12 cases and literature review. Ann Diagn Pathol. 2013;17:1821

2. Singh S, Garg KN, Gupta K, Bhat P. Papillary Squamous Cell Carcinoma: A Review. J Dentofac Sci. 2012;1:3-25.

3. Cardesa A, Nadal A. Carcinoma of the head and neck in the HPVera. Acta Dermatoven APA. 2011;20:164-65.

4. Stelow EB, Mills SE.Squamous Cell Carcinoma Variants of Upper Aerodigestive Tract. Am J Clin Pathol. 2005;124:S96-109.

5. Terada T. Papillary squamous cell carcinoma of the mandibular gingiva. Int $\mathrm{J}$ Clin Exp Pathol. 2012;5:707-9.

6. Thompson LDR. Squamous cell carcinoma variants of the head and neck. Curr Diagn Pathol. 2003;9:384-96.

7. Samir K, El-Mofty. HPV-Related Squamous Cell Carcinoma Variants in the Head and Neck. Head and Neck Pathol. 2012; 6:S55-62. 